\title{
THYRO-LINGUO-FACIAL TRUNK OF EXTERNAL CAROTID ARTERY: A RARE VARIATION
}

\author{
Rakesh Kumar Diwan*, Archana Rani*, Jyoti Chopra*, Navneet Kumar* \\ *Department of Anatomy, King George's Medical University, Lucknow, UP, India
}

\begin{abstract}
The complicated process of angiogenesis and remodelling which includes annexation and regression of vessels may give rise to variations in the branches of external carotid artery. The knowledge of variations in the branching pattern of external carotid artery (ECA) is important for surgical procedures in the neck region, such as radial neck dissection, catheterization, reconstruction of aneurysm, carotid endarterectomy and intervention radiology. The anatomical consequences of anomalous branching pattern of external carotid artery may have important clinical implications. A rare, common branch of the ECA, a thyro-linguo-facial trunk was found on right side in a 65 years old male cadaver during routine dissection. After giving a branch to thyroid gland as superior thyroid artery, this trunk ran forwards and medially as linguo-facial trunk and divided into lingual and facial arteries. The hypoglossal nerve was crossing the linguo-facial trunk.
\end{abstract}

Keywords: External carotid artery, thyro-linguo-facial trunk, variation, hypoglossal nerve.

\section{INTRODUCTION}

The common carotid artery bifurcates into internal carotid and external carotid arteries at upper border of thyroid cartilage in the carotid triangle. On right side, the common carotid artery arises from brachiocephalic trunk, on left side it arises directly from the arch of aorta. The superior thyroid, lingual, and facial arteries arise from its anterior surface, the occipital and posterior auricular arteries arise from its posterior surface and ascending pharyngeal artery arise from its medial surface [1]. The rich vascularity of most parts of head and neck (except brain and eye) is mainly maintained by the external carotid artery through its branches. The external carotid artery has numerous important anastomoses with the internal carotid artery and the vertebrobasilar system, thus ensuring blood circulation in case of disturbed cerebral blood flow. Like other great vessels of neck, the external carotid artery and its branches have numerous variations and their exploration is more than interesting for a better anatomical knowledge of neck. These variations pose a dangerous situation during surgeries like thyroidectomy, laryngectomy facio-maxillary surgeries, tonsillectomy, glossectomy and other neck surgeries. It is important for the elevation of various cutaneous and myocutaneous flaps for plastic and reconstructive surgeries of the head, neck and face, which depend on the external carotid artery for their blood supply [2].

\section{CASE REPORT}

A rare, common branch of the ECA, a thyro-linguofacial trunk was found on right side in a 65 years old male cadaver during routine dissection in the Department of Anatomy, King George's Medical University, Lucknow, UP. The history of the individual and the cause of death was not known. The topographic details of the external carotid artery was examined by casual dissection and photographed. The thyro-linguo-facial trunk was $1.6 \mathrm{~mm}$ below the carotid bifurcation from anterior surface of right common carotid artery. After giving a branch to thyroid gland as superior thyroid artery, this trunk ran forwards and medially around $1.7 \mathrm{~mm}$ as linguo-facial trunk and divided into lingual and facial arteries. The hypoglossal nerve was crossing the linguo-facial trunk. The lingual artery ascends vertically up crossed the internal laryngeal nerve, taking an oblique course it passed 
underneath the hypoglossal nerve and anterior belly of digastric muscle to enter digastric triangle. The facial artery passed upwards and forwards and reached posterior part of the submandibular gland (Fig. 1).

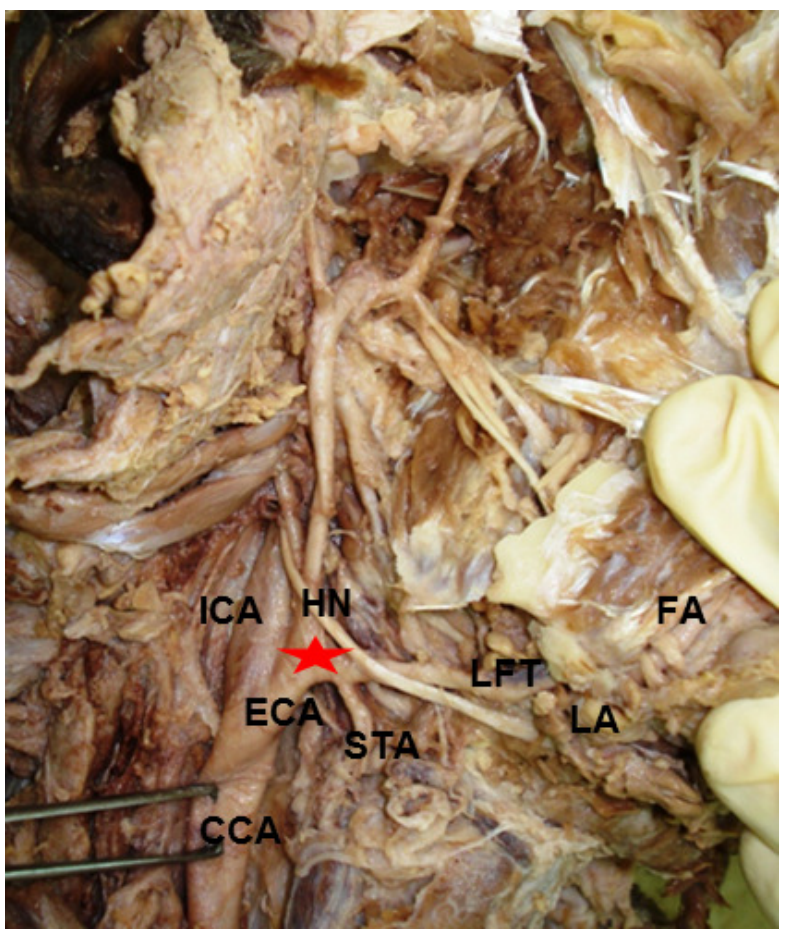

Fig. 1: Photograph showing thyro-linguo-facial trunk* (CCA-common carotid artery, ECA-external carotid artery, ICA-internal carotid artery, STA-superior thyroid artery, LFTlinguo-facial trunk, LA-lingual artery, FA-facial artery, $\mathrm{HN}$ hypoglossal nerve)

\section{DISCUSSION}

External carotid artery provides the major source of blood to the head and neck region. Variations in the branching pattern of it has been reported earlier. Aaron et al. (1970) reported the percentage of variants in the branching pattern of external carotid artery based on 113 specimens dissections. He described three different types of branching pattern i.e. "ladder division", "grouped division" and "bouquet division". He reported that linguofacial trunk was present in $20 \%$ of the cases, thyrolingual trunk in $5.9 \%$, thyrolinguo-facial trunk in $2.7 \%$. Out of these "bouquet division" was present in $2.7 \%$ and "ladder division" in 27.7\%" [3]. Zumre et al. (2005) observed linguo-facial trunk in $20 \%$, thyro-lingual trunk in $2.5 \%$, thyro-linguo-facial trunk in $2.5 \%$ and occipito- auricular trunk in $12.5 \%$ of cases in the human fetuses [4]. Anil et al. (2000) reported that lingual artery arises from a common trunk with the facial as a linguo-facial trunk in 10-20\% of cases [5]. Yildrim et al. (2001) observed total 6 $(15 \%)$ linguo-facial trunk in 40 neck side in human cadavers [6].

Ozgur et al. (2008) classified the origins of these arteries which were arising from the external carotid artery in 4 types and reported their incidences. The separate origins of the arteries were defined as type 1 $(90 \%$ of cases), the linguo-facial trunk as type 2 $(7.5 \%)$, the thyrolingual trunk as type $3(2.5 \%)$, and thyrolinguofacial trunk as type 4 [7].The development of external carotid artery system is a complicated process of angiogenesis and remodelling which includes annexation and regression of vessels. The development of hypostapedial artery which links the neural crest arterial system to the ventral pharyngeal artery marks an important event in the development of external carotid artery system [8].

The knowledge of variation in the origin of ECA is important for surgical procedures in the neck region such as radical neck dissection, catheterization, reconstruction of aneurysm, and interventional radiology. These variations pose a dangerous situation during various neck surgeries.

\section{REFERENCES}

1. Standring $S$, Johnson D, Ellis H, Collins $P$ (eds). Gray's Anatomy, $39^{\text {th }}$ ed. Churchill Livingstone: London. 2005, pp. 543-544.

2. Strauch B, Vasconez LO, Hall Findlay EJ. Grabb's Encyclopedia of flaps. $2^{\text {nd }}$ ed. Vol (1). Head and Neck. Philadelphia: Lippincott-Raven, 1998, pp. 989-997.

3. Aaron C, Doyon D, Fischgold H, Metzger J, Richard J. Arteriographie de la Carotide externe. Masson, Paris, 1970.

4. Zumre O, Salbacak A, Cicekcibasi AE, Tuncer I, Seker M. Investigation of the bifurcation level of the common carotid artery and variations of the branches of the external carotid artery in human foetuses. Ann Anat. 2005; 187(4): 361-369.

5. Anil A, Turgut HB, Peker T, Pelin C. Variations of the branches of the external carotid artery. Gazi Med J. 2000; 11(2):81-83.

6. Yildrim M, Tangeli E, Soyluogh A, Tuna Y. Truncus linguofacialis siklig.I. Morfologi Der; 2001 (Links): 9(1)33-34.

7. Ozgur Z, Govsa F, Ozgur T. Assessment of origin characteristics of the front branches of external carotid artery. $J$ Craniofac Surg. 2008; 19(4): 1159-66.

8. Larsen WJ. Human Embryology. $2^{\text {nd }}$ ed. Churchill Livingstone: New York, Edinburgh, London. 1997, pp. 191- 195. 